\title{
Transcatheter closure of Patent ductus arteriosus at Shahid Gangalal National Heart Centre, Kathmandu, Nepal
}

\author{
Chandra Mani Adhikari, ${ }^{1 *}$ Rabi Malla, ${ }^{1}$ Urmila Shakya, ${ }^{2}$ Manish Shrestha, ${ }^{2}$ Binay Rauniyar, ${ }^{1}$ Deepak Limbu, ${ }^{1}$ Poonam \\ Sharma, ${ }^{2}$ Milan Gautam, ${ }^{1}$ Shilpa Aryal, ${ }^{2}$ Ach hita $\mathrm{KC}^{1}$
}

1. Department of Cardiology, Shahid Gangalal National Heart Centre,Kathmandu, Nepal 2. Department of Paediatric Cardiology, Shahid Gangalal National Heart Centre, Kathmandu, Nepal.

\section{DOI Name}

http://dx.doi.org/10.3126/jaim.v6i1.18310

\section{Keywords}

Amplatzer duct occlude; patent ductus arteriosus; transcatheter closure.

\section{Citation}

Chandra Mani Adhikari, Rabi Malla, Urmila Shakya, Manish Shrestha, Binay Rauniyar, Deepak Limbu, Poonam Sharma, Milan Gautam, Shilpa Aryal, Achhita KC. Transcatheter closure of Patent ductus arteriosus at Shahid Gangalal National Heart Centre, Kathmandu, Nepal. Journal of Advances in Internal Medicine 2017;06(01):1-3.

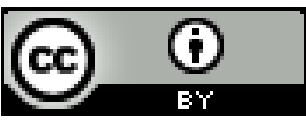

This work is licensed under a Creative Commons Attribution 3.0 Unported License.

\section{ABSTRACT}

Background and Aims: In the current era, transcatheter closure of patent ductus arteriosus (PDA) using either coils or device is a well-established procedure. The aim of this study was to assess safety of transcatheter closure of PDA at Shahid Gangalal national heart Centre, Kathmandu, Nepal.

Methods: It was a single centre, retrospective study conducted between March 2007 to March 2017. Cardiac catheterization laboratory records of all consecutive patients who underwent PDA device closure were included. A lateral view Aortic angiogram was performed to determine the morphology and size of the duct. Device type and size was selected as per the aortogram. A second aortic angiogram was performed 5 min after device deployment to determine the success of the closure. Echocardiography was done next day of the procedure to assess success of the closure.

Result: During the study period 126 patients were attempted for transcatheter closure of PDA. Six patient were thought to have unfavorable size or shape, and transcatheter occlusion was not attempted. In one patients attempt was made to close the duct with cook coil which embolized to pulmonary artery. One hundred and nineteen patient PDA was successfully closed. Among the 119 patients 89 were female and 30 were male. The PDA was closed by Amplatzer duct occluder in 99 patients, Life tech PDA occluder in 14 patients, Hyperion PDA occluder in two patients, Post-infarct Muscular VSD Occluder in four patients.

Conclusions: Transcatheter closure of PDA can be done safely with high success rate.

\section{INTRODUCTION}

Patent ductus arteriosus (PDA) is common form of congenital heart disease. PDA constitutes $6-11 \%$ of all congenital defects. It is estimated that PDA occurs about 1 in 2500-5000 live births. ${ }^{1}$

Closure of PDA is indicated only in patients with continuous murmur. Transcatheter closure of PDAs has assumed a major role in closure of PDA. ${ }^{2}$ Transcatheter closure is currently the preferred method of treatment of PDA. ${ }^{3}$

This study reports the experience at Shahid Gangalal National Heart Centre,Kathmandu, Nepal with percutaneous closure of PDA.

\section{METHOD}

It was a retrospective, single centre study, performed at Shahid Gangalal National Heart Centre, Kathmandu, Nepal. Cardiac catheterization laboratory records and Medical records of all consecutive patients who underwent PDA device closure from March 2007 March 2017 were retrospectively reviewed. Demographics of the patients were collected.

PDA device closure was done under universal aseptic condition

\footnotetext{
* Corresponding author

Chandra Mani Adhikari

Department of Cardiology

Shahid Gangalal National Heart Centre, Kathmandu, Nepal email address:topjhap@gmail.com
} 
through right femoral venous approach. A lateral view Aortic angiogram was performed to determine the morphology and size of the duct. Device type and size was selected as per the aortogram. A second aortic angiogram was performed $5 \mathrm{~min}$ after device deployment to determine the success of the closure. Echocardiography was done next day of the procedure to assess success of the closure.Complications of the procedure were recorded.

The study protocol was approved by institutional review board (IRB) of Shahid Gangalal National Heart Centre, Kathmandu, Nepal.

All the variables were entered into the Statistical Packagefor Social Sciences software, version 20(SPSS Inc., Chicago, IL, USA) for data analysis. Descriptive statisticswere computed and presented as means and standard deviations.

\section{RESULT}

During the study period 126 patients were attempted for transcatheter closure of PDA. Six patient were thought to have unfavorable size or shape, and transcatheter occlusion was not attempted. In one patients attempt was made to close the duct with cook coil which embolized to pulmonary artery. One hundred and nineteen patient PDA was successfully closed. Among the 119 patients 89 were female and 30 were male. Age ranged from one year to 69 years. with the mean of $16.6 \pm 12.7$ years.Size of PDA ranged from $3 \mathrm{~mm}$ to $14 \mathrm{~mm}$, with the mean of $5.7 \pm 2.7 \mathrm{~mm}$ The PDA was closed by Amplatzer duct occluder in 99 patients, Life tech PDA occluder in 14 patients, Hyperion PDA occluder in two patients, Amplatzer Post-infarct Muscular VSD Occluder in four patients, as shown in table 1. Hyperion and life tech are like amplatzer duct occluder. Device size $6 \times 8$ and $8 \times 10$ were the most commonly device size as shown in table 2.Among our subjects, we did not find any complication related to vascular access, hemolysis, and massive blood loss.

There was no evidence of obstruction of the left pulmonary artery or the descending aorta, as confirmed by 2D-Doppler in the following day follow-up. No death occurred in this study.

Table 1. Demographics

\begin{tabular}{lll}
\hline Variable & No & $\%$ \\
\hline Male & 30 & 25.2 \\
Female & 89 & 74.8 \\
Device type & & \\
Amplatzer duct occluder I & 99 & 83.1 \\
Hyperion & 2 & 1.6 \\
Post-infarct Muscular VSD Occluder & 4 & 3.2 \\
Lifetech & 14 & 11.7 \\
\hline
\end{tabular}

Table 2: Device size

\begin{tabular}{ll}
\hline Device size & \\
\hline $4 \times 6$ & 15 \\
$6 \times 8$ & 37 \\
$8 \times 10$ & 37 \\
$10 \times 12$ & 19 \\
$12 \times 14$ & 5 \\
$14 \times 16$ & 1 \\
$20 \times 22$ & 1 \\
Post-infarct Muscular VSD Occluder 16 & 1 \\
Post-infarct Muscular VSD Occluder 18 & 1 \\
Post-infarct Muscular VSD Occluder 20 & 1 \\
Post-infarct Muscular VSD Occluder 22 & 1 \\
\hline
\end{tabular}

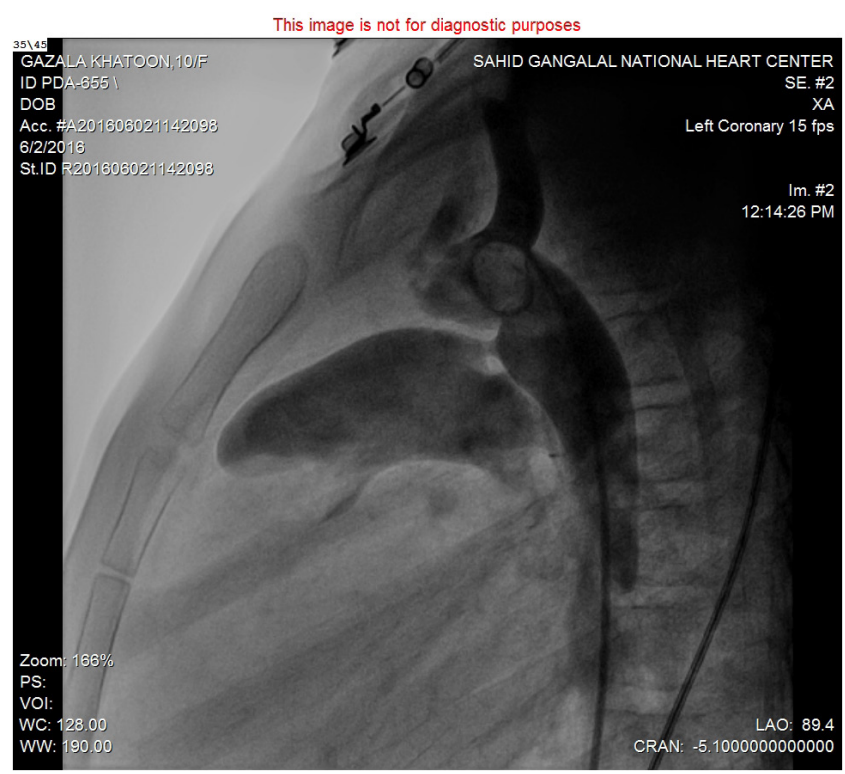

Fig 1. PDA in Lateral Aortogram

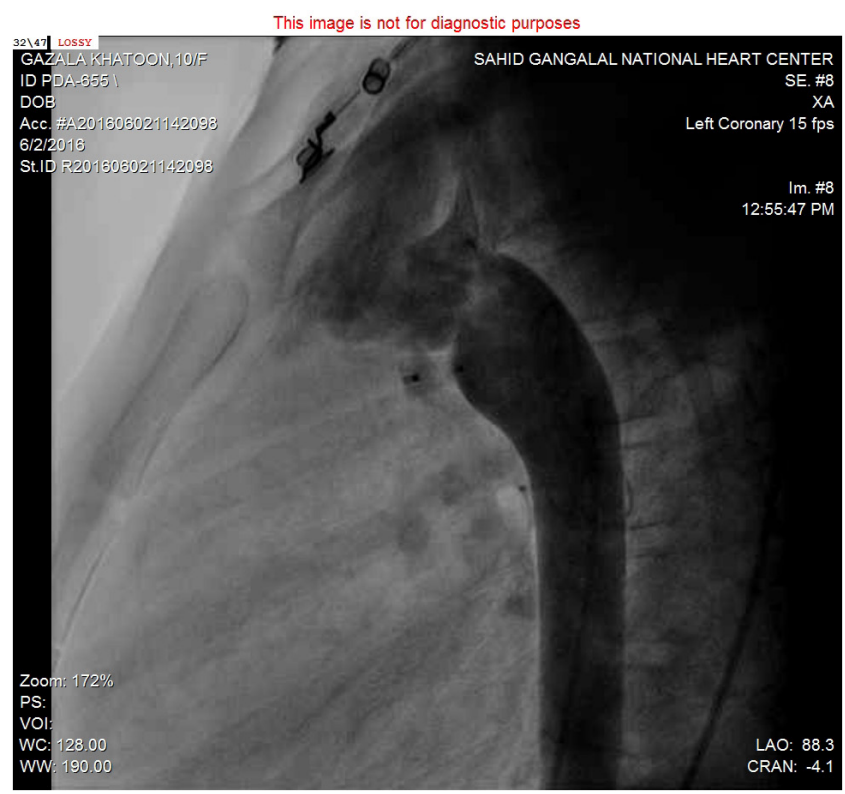

Fig 2. PDA closed with ADO $6 \times 8$ device. 


\section{DISCUSSION}

Transcatheter device closure of patent ductus arteriosus is a standard and well established technique. ${ }^{4}$ Coils and devices are used to close PDA. Amplatzer duct occluder is safe and commonly used device worldwide to close PDA. The success rate of Amplatzer duct occluder is high with minimal, either major or minor, complications. ${ }^{5}$ We were using this device as The transcatheter occlusion of large persistent PDA using Amplatzer prosthesis has shown to be highly effective procedure in large series. ${ }^{6}$

The results of our study of percutaneous PDA closure with the Amplatzer duct occluder, with an occlusion rate of $100 \%$ at 24 hours, concurs with results reported in other studies. ${ }^{7,8,9}$ Our success rate is similar to Egyptian study, there success rate is 98.4\%.$^{10}$ Overall PDA closure rate was $94 \%$ and major adverse events were $1.5 \%{ }^{11,12}$

In our study, there is no protrusion of the occlusion device into the aorta or obstruction to the LPA which are common complications of transcatheter closure of PDA our result is similar to study in Egyptian study. ${ }^{10}$

There are many advantages of PDA device closure compared to surgical ligation which include, less invasive, without surgical scar, short hospital course, low morbidity and comparable success rate. However, the surgical ligation is still necessary for large PDA especially in small infants.

Our study has certain limitations. Being a retrospective study, it is based on hospital database, so we could not comment on pre and post procedural clinical status of the patient. We cannot report the type of the PDA. Further, change in symptoms, and follow up study could not be included in the study.

\section{CONCLUSIONS}

In our experience, high success rate with low complications and residual shunts suggest that transcatheter closure of PDA is effective and safe with good outcome in most cases.

\section{REFERENCES}

1. Mulyadi M. Djer,Dimas Dwi Saputro, Sukman Tulus Putra, et al. Transcatheter Closure of Patent Ductus Arteriosus: 11 Years of Clinical Experience in Cipto Mangunkusumo Hospital, Jakarta,Indonesia. Pediatr Cardiol (2015) 36:1070-1074.

2. Yarrabolu TR, Syamasundar Rao P.Transcatheter Closure of Patent Ductus Arteriosus. Pediat Therapeut 2012, S5

3. Agnetti Aldo, Carano Nicola, Tchana Bertrand,et al. Transcatheter Closure of Patent Ductus Arteriosus: Experience with a New Device. Clin. Cardiol. 32, 11, E71E74 (2009)

4. Baruteau AE, Hascoët S, Baruteau J, et al.. Transcatheter closure of patent ductus arteriosus: past, present and future. Arch Cardiovasc Dis 2014;107:122-32.

5. Muhammad A. Khan, Yahya H. Almashham, Abdul Rahman S, et al. Embolized amplatzer duct occluder to aorta:Retrieval technique. J Saudi Heart Assoc 2016;28:116-118

6. Juliano Rathke, Hon.rio Sampaio Menezes, Raul Ivo RossiFilho,et al. Percutaneous Occlusion of Patent Ductus Arteriosus. Rev Bras Cardiol Invasiva. 2014;22(4):364-8
7. Aurora Fernández Ruiz, M. Jesús del Cerro Marín, Dolores Rubio Vidal, M, et al. Transcatheter Closure of Patent Ductus Arteriosus Using the Amplatzer Duct Occluder: Initial Results and Mid-Term Follow-Up. Rev Esp Cardiol 2002;55(10):1057-62

8. Podnar T, Masura J. Percutaneous closure of patent arterial ductus using special screwing detachable coil. Cath Cardiovasc Diagn 1997;41:386-91.

9. Thanapoulos D, Hakim FA, Hiari A, Goussos Y, Basta $E$, Zarayelyan $A A$, et al. Further experience with transcatheter closure of the patent ductus arteriosus using the amplatzer duct occluder. J Am Coll Cardiol 2000;35:1016-21.

10. Safaa Husein Ali, Sharaf Eldeen Shazly Abdalla. Percutaneous transcatheter closure of patent ductus arteriosus: Initial experience of Sohag University. The Egyptian Heart Journal (2014) 66, 143-147.

11 Krichenko MD, Lee N, Benson MD. Angiographic classification of the isolated persistently patent ductus arteriosus and implications for percutaneous catheter occlusion. Am J Cardiol1989;1:877-9.

12. Schneider DJ, Moore JW. Patent ductus arteriosus. Circulation 2006;114:1873-82. 